\title{
Assessment of mating management effect on genealogical parameters highlighting the genetic variability in a not closed fat-tailed Barbarine sheep pedigree
}

\author{
Abdellah Chalh', Dhouha Mansouri', Mohamed Ben Hamouda² and Mohamed El Gazzah' \\ 'Unité de Génétique des Populations et Ressources Biologiques, Université Tunis El Manar, Faculté des Sciences de \\ Tunis, Département de Biologie, Tunis, Tunisia, ${ }^{2}$ Institution de la Recherche et de I'Enseignement Supérieur Agricoles \\ (IRESA), Tunis, Tunisia
}

\begin{abstract}
The Barbarine sheep is generally managed within small interconnected herds. The goal of the present work is to investigate the effect of the mating management on genetic variability in a registered flock which starts showing a productivity falling, especially in lamb's survival and this despite a practice of outbreeding. Pedigree data of 11136 animals born between 1977 and 2007 were used to compute genealogical parameters. A first investigation of the lambs-parents relationships highlighted two periods that we denoted: P1 and P2. During P1, the mating strategy had been progressively based on animals born within the flock, whereas during $\mathrm{P} 2$, ewes and rams coming from outside the herd were gradually introduced as parents with unknown genealogy. This change in matings policy has been emphasised by plotting equivalent complete generations averaged whether by year of birth or maximum number of traced generations. All the computed genealogical parameters have been affected by the matings policy change and especially the individual average relatedness and realised effective size, which seem to be powerful tools to monitor the genetic variability within a population that is not closed to exchanges. An important effect of pedigree depth has been detected; this would require special attention to the matings of individuals with deepest genealogy. In spite of this effect, the heterozygote deficiency within the herd confirmed that the genetic variability has not been much affected along the flock life, which confirms that the decline in productivity should not be allotted to matings' policy, but probably to other management factors.
\end{abstract}

Keywords: Barbarine sheep, matings policy, inbreeding, outbreeding, pedigree parameters, genetic variability

\section{Introduction}

The fat-tailed Barbarine breed is the oldest sheep in Tunisia and accounts for $85 \%$ of the local sheep livestock. In spite of its importance, inbreeding has never been investigated even if the matings are generally assisted by the shepherds because of its fatty tail, " from 1 to $4 \mathrm{~kg}$ " following Atti et al. (2004). In fact, this morphological trait should, a priori, confer to breeders a paternity controlling convenience. However, in most regions of Tunisia, sheep breeds are generally managed in relatively small and little connected herds which imply that mating 
related or closely related individuals becomes more probable. This practice may consequently increase the inbreeding rate within herds (Wang \& Caballero 1999), reduce genetic variability (Caballero \& Toro 2000, Pariset et al. 2003), fix unfavourable alleles and generate inbreeding depression (Slate et al. 2004). The genetic explanation of this last phenomenon has been widely discussed in a recent work of Köck et al. (2009). If we consider one trait, the amount of the inbreeding depression will not be the same for all species or even within a given species. Recent studies have even reported that inbreeding depression shows a variation among founders of a population (Gulisija et al. 2006).

For sheep breeds, it has been shown that inbreeding was responsible for a significant reduction in more than one trait. In fact, many studies on various breeds have concluded that inbreeding is behind a reduction in lamb's survival and reproductive traits (William et al. 1982, Kalinowski \& Hedrick 2001, Mandal et al. 2004, Selvaggi et al. 2010). Other works on growth traits have shown that many of these traits are prone to inbreeding depression (Hussain et al. 2006a, 2006b; Norberg \& Sörensen 2007, Casellas et al. 2009, Selvaggi et al. 2010). However, and in the contrast with the preceding results, Swanepoel et al. (2007) confirmed that there is no significant inbreeding depression on body weight traits in the South African Dohne Merino breed. Overall et al. (2005) reported also that the inbreeding did not affect significantly either birth weight or neonatal survival in St Kilda Soay lambs.

Obviously, managing a flock in a closed system will generate inbreeding depressions for more than one trait in sheep. Furthermore, such system would lead certainly to a loss of genetic variability if the inbreeding rate is not maintained at a low level, especially when numbers of breeding males and females were unequal (Sánchez et al. 2003).

By introducing foreign purebred animals as founders, we should increase the genetic variability and any selection program must be elaborated by considering a suitable management of the genetic stock (Cervantes et al. 2008). Sörensen \& Norberg (2008) have recommended to Danish breeders to use more rotation of rams between flocks to reduce the rate of inbreeding in the small populations of local sheep breeds. Similar strategies were suggested by other authors (De Rochambeau \& Chevalet 1985, De Rochambeau et al. 2000).

In the present study we will investigate the effect of the mating policies practiced during more than thirty years on some genealogical parameters by using a pedigree of an experimental flock of the purebred Barbarine sheep that usually received foreign noninbred individuals as parents. This in order to determine which parameter is more appropriate to evaluate the genetic variability in this case. In spite of the outbreeding practice, the studied population starts showing some problems like productivity falling despite the fact that mating relatives was generally avoided. That is why, we will also attempt to show if this decline in fitness is the result of a decrease in genetic variability due to the inbreeding.

\section{Material and methods}

An initial purebred Barbarine sheep pedigree containing more than 11600 individuals born between 1977 and 2007 was edited. The data were recorded in an experimental herd raised in central region of Tunisia. Several checks and corrections were carried out in order to elaborate a free relationships errors pedigree file and all individuals with doubtful relationships were discarded from the original pedigree by discarding incomplete identifiers. Only rams and 
ewes born in the flock were considered as known parents, whereas foreign parents were considered unknown. Hence, a final file containing 11136 individuals was elaborated and individual inbreeding coefficients were calculated following VanRaden (1992) algorithm implemented in the fortran software PEDIG elaborated by Boichard (2002). The base population represents $12.9 \%$ of all pedigree. Other genealogical parameters, like: maximum number of traced generations, equivalent complete generations, individual average relatedness, average coancestry, founder genome equivalent and effective population size were computed by using ENDOG of Gutiérrez \& Goyache (2005).

The kind of mating management is not clear, so since lambing occurs once a year, we used parent's information to determine the following four complementary frequencies: lambs born by mating both known parents, lambs born by mating known ram and unknown ewe, lambs born by mating unknown ram and known ewe and finally lambs born by mating both foreign parents. In order to avoid that a relative counts more than one time, only single born lambs and one of twins were considered at this step of work. Parents with integral identifiers but not born in the flock were considered as unknown since they come generally from flocks where pedigree is uncontrolled. The computed frequencies, represented as a $100 \%$ piled surfaces diagram (Figure 1), will then inform us on how the matings were managed along thirty one years. Mainly two periods are noticeable on this figure. A first one (1977-1989), that we denote P1, where the mating policy had been progressively based on animals born within the flock; and a second period (1989-2007), denoted P2, where foreign blood was progressively introduced in the experimental flock. Thus, it would be interesting to investigate the effect of this change on the genealogical parameters, especially those highlighting the genetic variability.

\section{$100 \%$ Piled surfaces diagram}

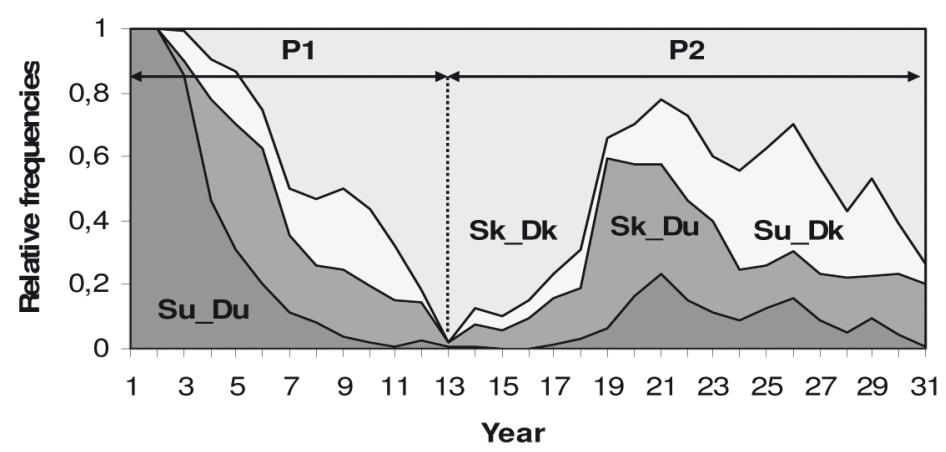

Sk_Dk: lambs born by mating known ram and ewe, Sk_Du: lambs born by mating known ram and unknown ewe, Su_Dk: lambs born by mating unknown ram and known ewe, Su_Du: lambs born by mating unknown ram and ewe. Sires and dams were considered unknown if they were not born within the herd.

Figure 1

Frequencies of lambs following the origin of their parents

The maximum number of traced generations is computed as the number of generations separating the lamb from its furthest known ancestor in each path. Ancestors with unknown parents were assigned to generation 0 . The equivalent complete generation is calculated for the pedigree of the individual as the sum over all known ancestors of the term of $(1 / 2)^{n}$, where $n$ is the number of generations separating the individual from each known ancestor. 
The individual coefficient of inbreeding $F$ (Malécot 1948) is defined as the probability that an individual has two identical alleles by descent, while the individual average relatedness coefficient AR (Goyache et al. 2003, Gutiérrez et al. 2003) represents the probability that if an allele has been randomly chosen from the whole population it will belong to the animal. The former parameter is computed for each individual in the pedigree as the average of the coefficients corresponding to the animal row in the numerator relationship matrix $A$. The mean of the coefficients of this matrix represents twice the average kinship coefficients $f$ (or coancestry). The AR accounts simultaneously for the coancestry and inbreeding coefficient (Gutiérrez et al. 2005) and can be used as an index to maintain a genetic stock by mating animals with lowest AR (Goyache et al. 2003).

Under random mating, coancestry is comparable with inbreeding and with half relationship.

In order to evaluate the effect of the mating management on the genetic variability, we computed the founder genome equivalents $(\mathrm{Ng})$ defined as the overall founder representation in a managed population accounting for the loss of genetic variability from unequal founder and non-founder contributions (Lacy 1995). This parameter is also calculated from the additive relationship matrix (Caballero \& Toro 2000). $\mathrm{Ng}=1 / 2 \Delta f$ ( $\Delta f$ being here the average kinship coefficients $f$ in a considered subpopulation.

All the above parameters were averaged per year of lambing and also per maximum number of traced generations in order to assess the pedigree depth effect.

For further investigation of the genetic variability evolution, two other parameters are computed:

1) the effective population size, which is defined as the number of breeding animals that would lead to the actual increase in inbreeding if they contributed equally to the next generation. This parameter was estimated for nine subpopulations defined by nine successive periods of three years each starting from the fifth year. The approach used in this work is this recently proposed by Gutiérrez et al. (2008) in the form proposed by Gutiérrez et al. (2009). For each individual, a $\Delta \mathrm{F}_{\mathrm{i}}$ is computed as:

$$
\Delta F_{i}=1-\sqrt[t-1]{1-F i}
$$

where $F i$ is simply the individual inbreeding coefficient and $t$ is the "equivalent complete generations", as defined before. The effective population size, which will be named in this work "realised effective size" as Cervantes et al. (2008) and recently Mucha et al. (2011), is computed from $\overline{\Delta F}$ (the average of $\Delta F_{i}$ of $n$ individuals included in a reference subpopulation), as $\overline{N e}=1 /(2 \overline{\Delta F})$. This way of estimating effective population size depends only on the matings carried out throughout the pedigree of each individual and not on the mating management of the whole reference subpopulation. Moreover, a standard error of the $\overline{N e}$ estimation can be obtained by this method as described in Gutiérrez et al. (2008).

2) the Wright's $F_{\text {IS }}$ statistics (cited in Álvarez et al. 2008) which is defined as heterozygote deficiency within population by:

$$
F_{\text {IS }}=\frac{\bar{F}-\bar{f}}{1-\bar{f}}
$$


with $\bar{F}$ : the mean of the inbreeding coefficient in whole population and $f$ is the average coancestry for each defined time period. This parameter measures the departure from random mating as a deviation from Hardy-Weinberg proportions.

Starting from the fifth year in the pedigree, both $\overline{N e}$ and $F_{\text {IS }}$ were computed for nine successive periods of three years each; and also for subpopulations defined on the basis of the maximum number of traced generations.

\section{Results}

\section{Analysis of generations}

The average age of parents at lambing, are: 3.57 years \pm 0.02 and 4.11 years \pm 0.03 for rams and ewes, respectively. Theoretically, when a population is closed to exchanges, the equivalent complete generation should, in average, linearly increase with time. Interestingly, one can see how the change in mating policy (as revealed in Figure 1) has affected this relation. By representing the equivalent complete generations averaged by year of birth (Figure 2a), we noticed indeed that this parameter increases linearly along the first nineteen years; then decreases to stabilise around two years. By referring to Figure 1, this change coincides with the beginning of an intense practice of outbreeding. To allow tracking the evolution according to pedigree depth, the same parameter has been averaged by maximum number of traced generations (Figure 2b). Mean equivalent complete generations increases linearly with depth of the pedigree, but when matings policy has changed at the beginning of $\mathrm{P} 2$ period (generations: 5, 6, 7 and 8 ) the mean equivalent complete generations has been kept relatively stable at 2.5 . For the deepest generations (i.e. 9, 10 and 11), on which the outbreeding practice has progressively decreased, the mean of equivalent complete generations increases linearly again. Hence, each of the two previous analyses could be used as a straightforward tool to detect periods of intense practice of outbreeding in a not closed pedigree.
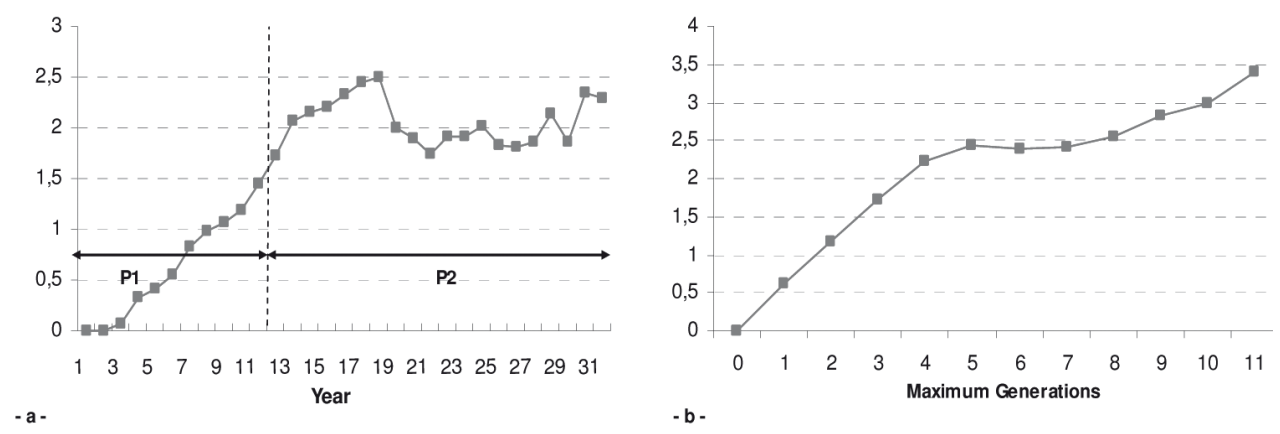

Vertical dashed line indicates also the year when individuals of generation 5 appear for the first time.

Figure 2

Mean equivalent complete generations represented by year of birth [-a-] and by maximum number of traced generations [-b-] 


\section{Inbreeding}

The summary of the inbreeding statistics is given in Table 1. Number of lambs born in the flock is 9699 of which more than $15 \%$ are inbred. The average inbreeding in the whole pedigree (excluding base population) is $0.41 \%$; and $2.20 \%$ if only inbred animals were considered. About $87 \%$ of inbred animals have inbreeding coefficients lower than $5 \%$ (Figure 3 ).

Table 1

Inbreeding statistics

Whole pedigree size

Number of lambs born in the flock

11136

Number of inbred animals

9699

Average inbreeding of all animals (excluding the base population)

Average inbreeding (of inbred animals)

$1470(15,16 \%)$

$0.41 \%$

$2.2 \%$

Inbreeding coefficient maxima

$26.03 \%$

Highly inbred matings

Between half-sibs: 42 (0.43\%)

Between parents-offspring: $13(0.13 \%)$

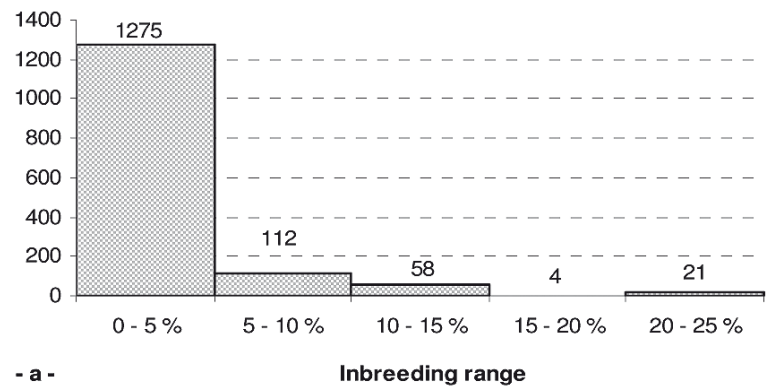

Figure 3

The inbreeding coefficients

distribution in inbred animals

In Figure 4a, we represented the average inbreeding of all animals by year of lambing. During the first four years, inbreeding coefficients are zero since all parents were considered noninbred. One can conclude that during the P1 period, the average coefficient of inbreeding was low then increases at the last year. After the first six years of $P 2$, the inbreeding decreased after intense introduction of unknown parents as it appears in Figure 1. At the last two years of $\mathrm{P} 2$, the average coefficient of inbreeding increases, once again, because few foreign parents were introduced as shown in Figure 1, and certainly because a pedigree depth effect. In fact, the same parameter represented by maximum number of traced generations (Figure $4 \mathrm{~d}$ ) has shown that individuals with deep pedigree are in average more inbred. When only inbred animals were considered (Figure 4b), it appears that average coefficient of inbreeding was high at P1 period showing a diminution trend; while a stability at low level of inbreeding characterise the $\mathrm{P} 2$ period. This shows that the adopted strategy maintained successfully the inbreeding level on a bottom grade. However, by taking into account the depth of the pedigree (Figure 4e), we realise that individuals representing the deepest generation (11) have an average inbreeding coefficient greater than six times that of individuals of other generations. In proportion terms (Figure 4c), we can notice that more individuals were inbred in P2 period as consequence of pedigree depth as shown in Figure $4 \mathrm{f}$. Especially since little individuals were born from mating both unknown parents during this period (Figure 1). The individuals with deepest pedigree give proportionally more inbred lambs than those with a shallow one. 

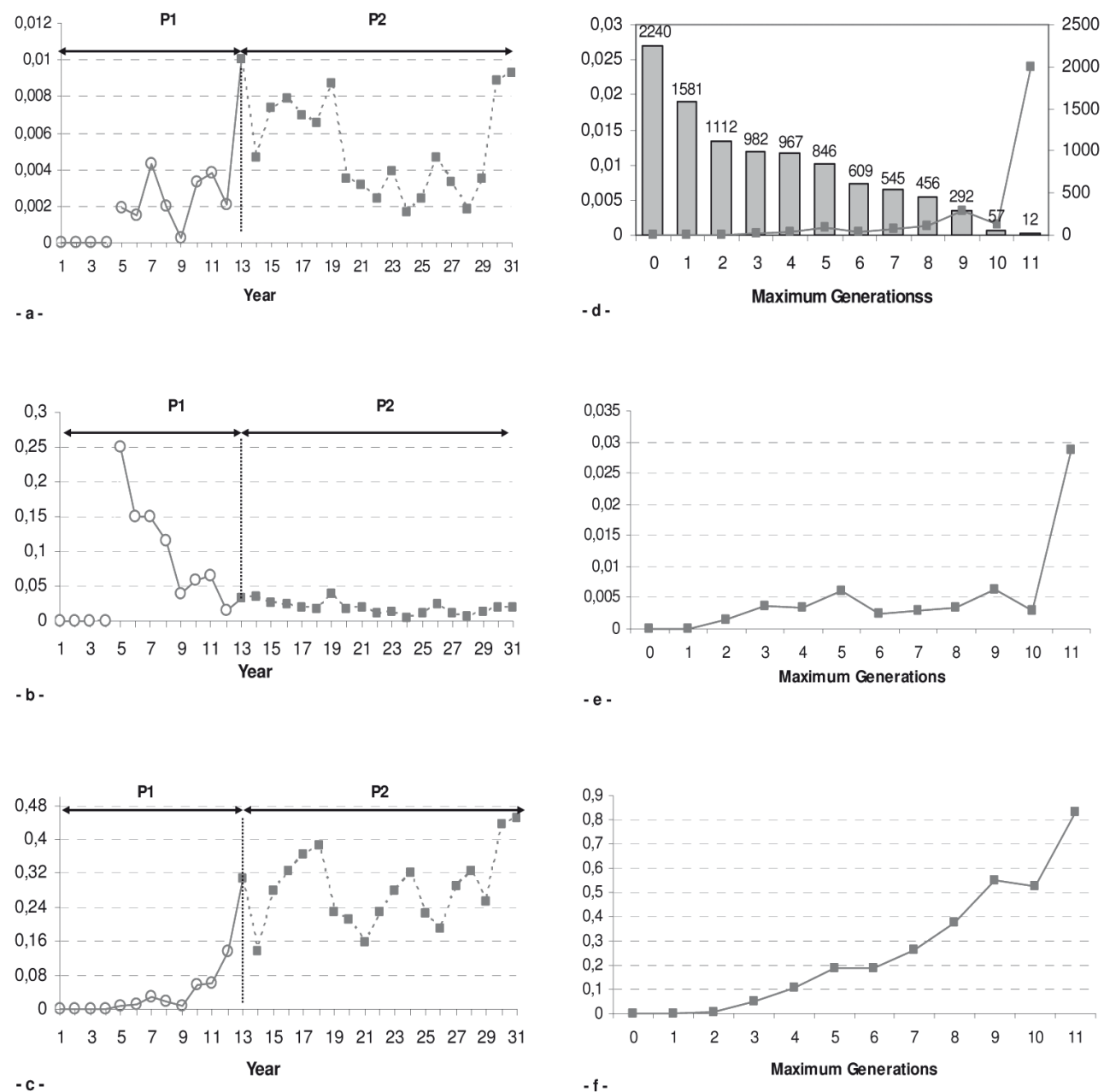

Vertical dashed line indicates also the year when individuals of generation 5 appear for the first time.

Figure 4

Inbreeding evolution across years of birth and by maximum number of traced generations: [-a- and - $d-]$ in all pedigree, [-b- and -e-] considering only inbred animals and [-c- and - $-\mathrm{f}-]$ inbred animal frequencies

\section{Average coancestry and founder genome equivalent}

The average coancestry parameter is represented in Figure 5a which shows two distinct behaviours, an increasing trend during P1 reaching 0.014 and a relative stability around 0.008 during $\mathrm{P} 2$. Thus, one can deduce that during P1, there was a progressive loss in genetic variability that was stopped by introducing foreign parents during P2. Nevertheless, there was certainly a genetic mixing between flock individuals and the introduced animals, what should instead generate an increasing genetic variability within the flock. Especially, most matings have occurred, during the beginning of $\mathrm{P} 2$, between foreign parents and those born in the flock as shown in Figure 1. Interestingly, a representation of the coancestry averaged 
by maximum generations (Figure 5c) revealed, as inbreeding, an increase in coancestry between individuals with deepest pedigree (generations 10 and 11). In fact, at the end of P2 period (Figure 1), most of matings occurred between animals born within the herd.
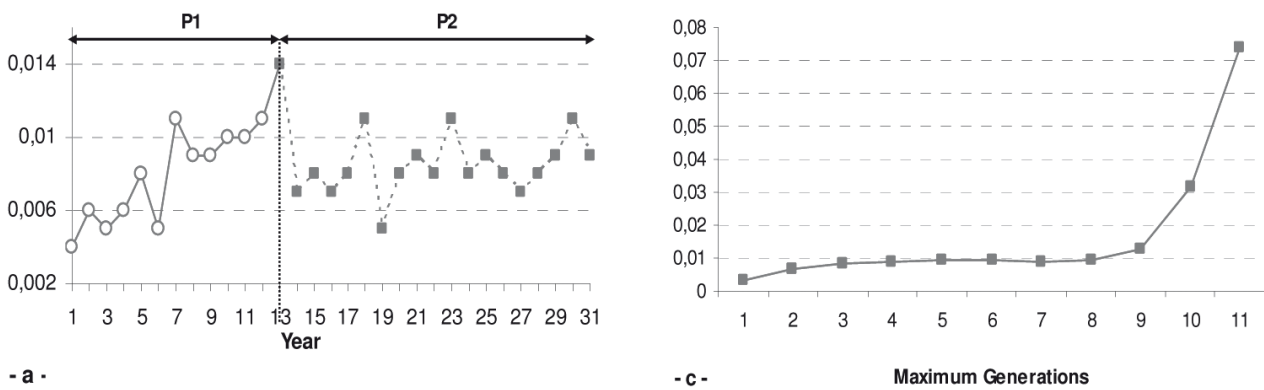
$-\mathbf{a}$
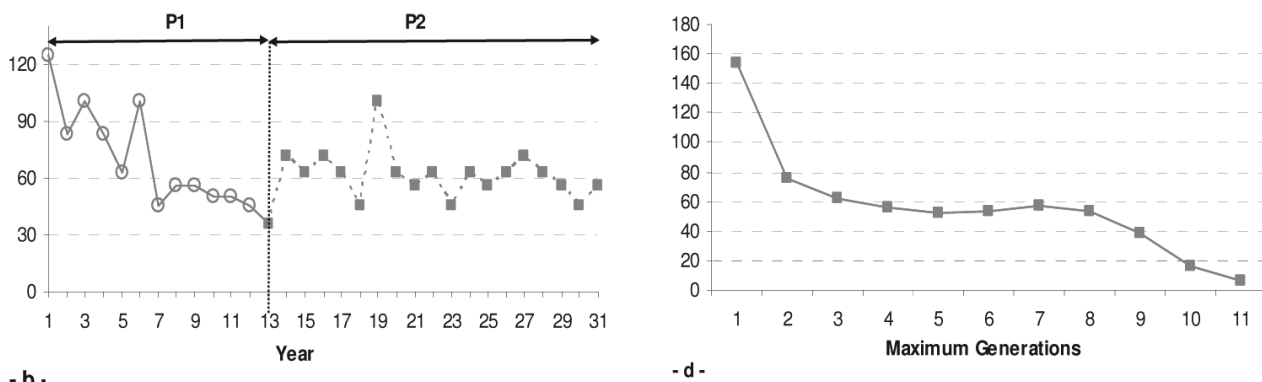
- b .

Vertical dashed line indicates also the year when maximum generation 5 appears for the first time.

\section{Figure 5}

Evolution of average coancestry and founder genome equivalent over years of birth [-a- and -b-] and across maximum number of traced generations [-c- and - $d-]$

The evolution of the founder genome equivalent $(\mathrm{Ng})$ along years is represented in Figure 5. During P1 this parameter decreases as predicted from the average coancestry since both criteria were inversely proportional. This result highlights a decreasing genetic variability due to unequal founder and non-founder contributions. At P2 period, the $\mathrm{Ng}$ keeps the same stability aspect as noticed for the average coancestry parameter. The outbreeding practiced mainly at the beginning of $\mathrm{P} 2$ period has consequently balanced founders' contribution, what allowed certainly a prevention of alleles' loss. By considering pedigree's depth (Figure 5), one can notice that after the outbreeding decrease at the end of $\mathrm{P} 2$, animals whose genealogy goes back to the initial founders contribute unevenly to the genetic pool of the population compared to non-founders; what should certainly reduce the genetic variability.

\section{Individual average relatedness}

As we reported in a previous section, the average relatedness (AR) that we represented in Figure 6a, takes into accounts both coancestry and inbreeding. Like the average coancestry, the individual average relatedness shows an increasing trend during $\mathrm{P} 1$, but it presents 
rather a clear decreasing tendency along P2 period. We can say hence, that the AR parameter seems to reflect much more the progressive genetic mixing that characterised this period. Nevertheless, when we considered the evolution of this parameter along generations (Figure $6 \mathrm{~b}$ ), we found an interesting behaviour. In fact, when outbreeding has been intensely practiced, i.e. at the beginning of P2 (generations: 6, 7 and 8), the AR parameter has consequently decreased; while at the end of this period (generations: 9, 10 and 11), the upward trend is back again. This is certainly due to the relatively high inbreeding and coancestry of individuals with deepest pedigree which are increasingly mated with other animals with a not shallow pedigree.
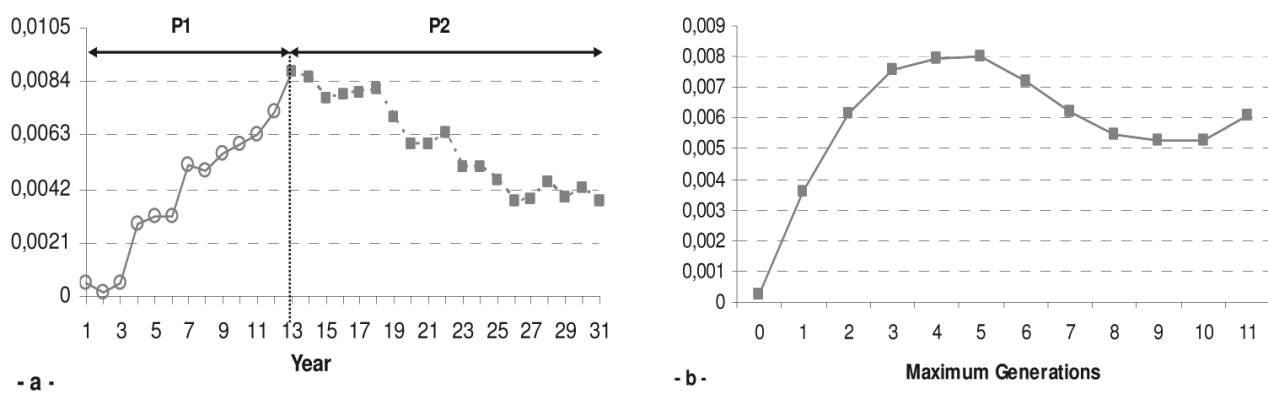

Vertical dashed line indicates also the year when maximum generation 5 appears for the first time.

Figure 6

Evolution of the average relatedness (AR) over years of birth [-a-] and across maximum number of traced generations [-b-]

\section{Realised effective size and heterozygote deficiency within the population}

The realised effective sizes $(\overline{\mathrm{Ne}})$, relating to nine subpopulations defined by successive periods of three years each, were represented in Figure 7a. It appears that the change in mating policy at $\mathrm{P} 2$ period had improved effectively the genetic variability within the herd, mainly when most matings occurred with at least one animal from outside the herd (i.e. between years 19 and 28). This result supports what we have previously reported on the outbreeding effect. Beyond the year 28 , one can notice that $\overline{\mathrm{Ne}}$ decreased as expected following a change in mating strategy that starts focusing, once again, on animals with known pedigree. By redefining the subpopulations on the basis of the maximum number of traced generations (Figure 7), we found that mainly animals with deepest pedigree (i.e. generation 11) have lost genetic variability under inbreeding. In fact, the estimated realised $\overline{\mathrm{Ne}}$ was under the critical level 50 set by FAO (1998), which corresponds to a rate of inbreeding of $1 \%$ per generation.

The heterozygote deficiency within the population $\left(\mathrm{F}_{15}\right)$ was computed by considering the same periods as before, and the obtained values were reported in Table 2 . $F_{\text {IS }}$ computed per maximum number of traced generations are in Table 3 . One can note that all $F_{\text {IS }}$ values were negative implying that inbreeding has never exceeded coancestry between individuals. This is certainly due to the outbreeding, what confirms the wise choice of this practice by the herd managers who have successfully monitored matings by avoiding most of those between close relatives. 

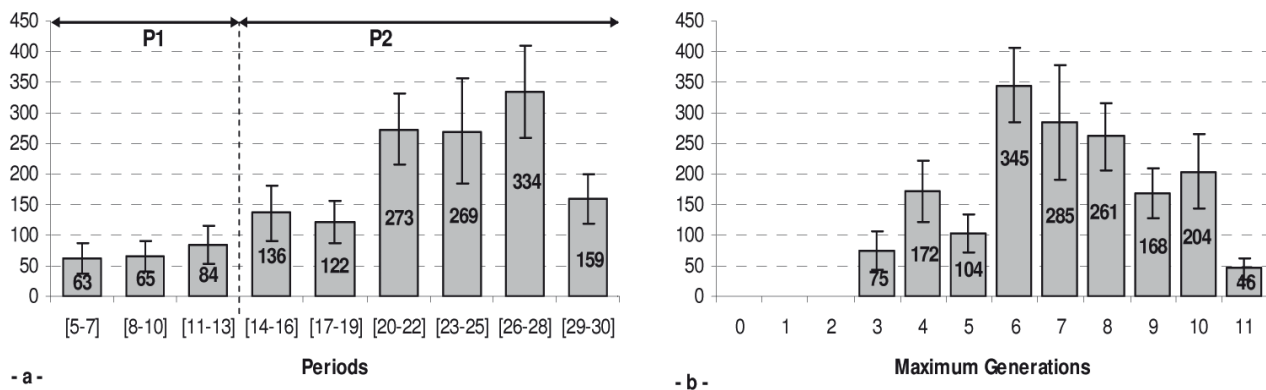

Vertical dashed line indicates also the year when maximum generation 5 appears for the first time.

\section{Figure 7}

Realised effective size $(\overline{\mathrm{Ne}})$ of subpopulations defined by nine successive periods [-a-] and by maximum number of traced generations [-b-]

Table 2

Wright's $F_{15}$ statistics estimated for nine successive periods

\begin{tabular}{lccccccccc}
\hline Periods & {$[5-7]$} & {$[8-10]$} & {$[11-13]$} & {$[14-16]$} & {$[17-19]$} & {$[20-21]$} & {$[22-24]$} & {$[25-27]$} & {$[28-31]$} \\
$\mathrm{F}_{1 \mathrm{~S}}\left(\times 10^{-4}\right)$ & -6.91 & -6.76 & -6.68 & -6.9 & -6.32 & -6.41 & -6.1 & -5.4 & -6.51 \\
\hline
\end{tabular}

Table 3

Wright's $F_{\text {Is }}$ statistics estimated by maximum number of traced generations

\begin{tabular}{lcccccccccccc}
\hline Max Generations & 0 & 1 & 2 & 3 & 4 & 5 & 6 & 7 & 8 & 9 & 10 & 11 \\
$\mathrm{~F}_{\text {IS }}\left(\times 10^{-4}\right)$ & -10.4 & -7.2 & -6.9 & -6.6 & -7.0 & -7.1 & -6.2 & -6.2 & -6.3 & -6.3 & -4.9 & -5.3 \\
\hline
\end{tabular}

\section{Discussion}

Without genetic variability, animals cannot neither adapt to environmental changes nor respond to selection (van Wyk et al. 2009). Therefore, it's necessary to have a reliable and straightforward tool to control this potential.

The average value of inbreeding in all Xalda population (an endangered sheep breed of Asturias region in Spain) was $1.5 \%$ (Goyache et al. 2003). For a closed Booroola breed (introduced in Poland from New Zealand), Rzewuska et al. (2005) reported that the average inbreeding coefficients of lambs, ewes and rams were: 6.0, 4.07, and 3.53\%, respectively. Lower values were reported by Boujenane \& Chami (1997) for two Moroccan sheep breeds; in the Sardi sheep they reached $2.82,1.04$ and $1.44 \%$, respectively, while $0.48,0.53$ and $0.04 \%$ were calculated in Beni Guil sheep. However, when only inbred animals were considered, the average inbreeding values in Beni Guil breed were $18.4 \%, 17.9 \%$ and $25.0 \%$, respectively; while in Sardi breed they reached: $32.8,31.3$ and $12.5 \%$.

For a rare breed, Álvarez et al. (2008) have shown that almost all of genealogical parameters vary according to the pedigree depth. Since Barbarine sheep is not an endangered breed, the mating management, as well as the connection between flocks should be more influential on these parameters. The studied population is not closed to exchange and periodically foreign noninbred animals were introduced as parents. The inbreeding level in the Barbarine breed seems to be low regarding the values reported for other breeds. For comparable sheep breeds, 
Pedrosa et al. (2010) and Navid Ghavi (2012) have reported greater values. This result reflects the success of the adopted mating strategy. However, under the pedigree depth, more lambs are born inbred. But, with an experimental herd, where also some selection schemes were tested, the inbreeding is not avoidable (Ghafouri-Kesbi et al. 2008). Nevertheless, in spite of this broad proportion, it is possible to maintain or even minimise inbreeding rate by managing the matings at each generation following specific strategy like this proposed by Sánchez et al. (2003).

Following Álvarez et al. (2008), the average coancestry may be considered, for rare breeds, as the better criterion to monitor genetic variability than other classical pedigree parameters. However, for the Barbarine breed, this parameter averaged by year of birth has shown a decreasing genetic variability during $\mathrm{P} 1$ period, but unfortunately it failed to reflect the effect of progressive introduction of foreign parents that should theoretically increase gradually the genetic variability during P2. We can deduce that when a population is not closed to exchange and/or managed following a system that focuses on dodging the matings between relatives, the annual average coancestry may not be considered as suitable for controlling genetic variability. However, when pedigree depth is considered, the average coancestry may be useful for detecting generations that should be targeted by the matings management.

The founder genome equivalent, represented by year of birth, has shown an opposite trend to the average coancestry parameter evolution during P1 and a similar behaviour during P2. Thus, we can suggest that both of these parameters, as defined here, are not appropriate to carry out a progression of a genetic mixture effect investigation but they can be used to fix generations which are sources of genetic variability losses.

Oliehoek et al. (2006) have reported that an increase in the number of generations increased pedigree relatedness and decreased the number of alleles surviving from the base to the current generation. This will be true for closed pedigree. In fact, we showed in this work that the average relatedness follows faithfully the influence of introducing progressively foreign parents by considering either years of birth or maximum number of traced generations. Thus, one can conclude that the genetic variability within an open flock might be monitored more appropriately by using the average relatedness; even if the population is not concerned by a conservation program as argued by Oliehoek et al. (2006). A similar conclusion was carried out by Goyache et al. (2003) and Ghafouri-Kesbi et al. (2008).

The effective population size is the most used parameter to carry out genetic variability investigations and classify populations especially for degrees of endangerment (Duchev et al. 2006 and Mucha et al. 2011). In a recent work, Cervantes et al. (2011) proposed a method to compute this parameter from increase in coancestry instead of inbreeding, but unfortunately the computing cost of their approach is exorbitant.

The realised effective size $\overline{N e}$ allowed us to reveal the effect of the outbreeding, as well as a reducing effect of individuals with deepest pedigree on the genetic variability (i.e. $\overline{N e}=46$, for generation 11). This result agrees with what have reported Álvarez et al. 2008 on the pedigree depth effect. This one should be attenuated in our case by mating one of the parents of the last generation with an individual from outside the herd or with one whose pedigree is a shallow one. A threshold for the expected equivalent complete generation of offsprings may also be defined for managing matings of individuals with deepest genealogy.

Regarding our results, one can conclude that the realised effective size $\overline{\mathrm{Ne}}$ may be considered as a better tool to monitor the genetic variability even if the population is not an endangered one. Its use would be more suitable if outbreeding is practiced in a population 
whose size much fluctuates as it was the case in our study. In fact, the realised effective size accounts for mating policy, bottlenecks due to excessive use of certain animals (Cervantes et al. 2008) and the differences in individual pedigree knowledge (Gutiérrez et al. 2008).

Let us recall that one of the main objectives of the present study was to show if the herd productivity decrease is attributed to a reduction in its genetic variability. The inbreeding level as well as the computed heterozygote deficiency within the population $\left(F_{15}\right)$ confirmed that the genetic variability was relatively well conserved. This is due to the fact that the studied population was not closed to exchanges and the matings between close relatives were generally avoided. This result agrees with what have reported Toro et al. (2000). Nevertheless, in order to confirm that there is no inbreeding depression it is recommended to remake the previous studies on growth traits, like this carried out by Djemali et al. (1994) by considering the inbreeding as covariate in the statistical model (Casellas et al. 2009, Selvaggi et al. 2010).

In conlusion, in the present study, we showed that the inbreeding in the studied population is sufficiently controlled and that the genetic variability has been maintained by introducing unknown parents that we considered here as noninbred founders. This practice had influenced substantially all genealogical parameters and had also attenuated the pedigree depth effect during a period of intense outbreeding practice. However, it has been showed that individuals with deepest genealogy should be particularly targeted by the matings management in order to decrease their reducing effect on genetic variability; especially if there is a decline in outbreeding practice. We argued in this work, that all used parameters, primarily the average relatedness and realised effective size are more appropriate to control genetic variability level within the population if purebred (even if unknown) parents were introduced.

Even if the herd productivity has decreased during last years, there was no evidence of a drastic loss of the genetic variability. Hence, the empirical diminution in some productive traits, primarily the lambs' survival, can be ascribed rather to some environmental and/or management factors. So, their improvement may be achieved by identifying and improving these factors.

Unfortunately, the luck of the genealogical information of the introduced parents has limited our investigation. It will be very interesting to confront our results with a molecular investigation, like those based on the microsatellite. This should bring more clarification to our arguments.

\section{Acknowledgements}

We thank all the OEP "Office de l'Elevage et des Pâturages of TUNISIA« teams who ensured relationships control and provided us their precious pedigree file. The authors are also grateful to anonymous referees who helped to improve the quality of the manuscript throughout their precious suggestions and constructive comments.

\section{References}

Álvarez I, Royo LJ, Gutiérrez JP, Fernández I, Arranz JJ, Goyache F (2008) Relationship between genealogical and microsatellite information characterising losses of genetic variability: Empirical evidence from the rare Xalda sheep breed. Livest Sci 115, 80-88

Atti N, Bocquier F, Khaldi G (2004) Performance of the fat-tailed Barbarine sheep in its environment: adaptive capacity to alternation of underfeeding and re-feeding periods. A review. Anim Res 53, 165-176

Boichard D (2002) Pedig: a Fortran package for pedigree analysis suited to large populations. In: Y. Van Der Honing (ed.), Proceedings of the 7th World Cong Genet Appl to Livest Prod, Montpellier, 19-23 August 2002, France, comm No. 28-13 
Boujenane I, Chami A (1997) Effects of inbreeding on reproduction, weights and survival of Sardi and Beni Guil sheep. J Anim Breed Genet 114, 23-31

Caballero A, Toro MA (2000) Interrelations between effective population size and other pedigree tools for the management of conserved populations. Genet Res 75, 331-343

Casellas J, Piedrafita J, Caja G, Varona L (2009) Analysis of founder-specific inbreeding depression on birth weight in Ripollesa lambs. J Anim Sci 87, 72-79

Cervantes I, Molina A, Goyache F, Gutiérrez JP, Valera M (2008) Population history and genetic variability in the Spanish Arab Horse assessed via pedigree analysis. Livest Sci 113, 24-33

Cervantes I, Goyache F, Molina A, Valera M, Gutiérrez JP (2011) Estimation of effective population size from the rate of coancestry in pedigreed populations. J Anim Breed Genet 128, 56-63

De Rochambeau H, Chevalet C (1985) Minimising inbreeding rates in small populations of domestic species. Genet Sel Evol 17, 459-480 [in French]

De Rochambeau H, Fournet-Hanocq F, Vu Tien Khang J (2000) Measuring and managing genetic variability in small populations. Ann Zootech 49, 77-93

Djemali M, Aloulou R, Ben Sassi M (1994) Adjustment factors and genetic and phenotypic parameters for growth traits of Barbarine lambs in Tunisia. Small Rumin Res 13, 41-47

Duchev Z, Distl O, Groeneveld E (2006) Early warning system for loss of diversity in European livestock breeds. Arch Tierz 49, 521-531

FAO (1998) Secondary guidelines for development of national farm genetic resources management plans: management of small populations at risk. FAO, Rome

Ghafouri-Kesbi F, Eskandarinasab M, Hassanabadi A (2008) Investigation of genetic variability and inbreeding characteristics in a population of Zandi sheep. Can J Anim Sci 88, 409-417

Goyache F, Gutiérrez JP, Fernández I, Gomez E, Alvarez I, Díez J, Royo LJ (2003) Using pedigree information to monitor genetic variability of endangered populations: the Xalda sheep breed of Asturias as an example. J Anim Breed Genet 120, 95-105

Gulisija D, Gianola D, Weigel KA, Toro MA (2006) Between-founder heterogeneity in inbreeding depression for production in Jersey cows. Livest Sci 104, 244-253

Gutiérrez JP, Altarriba J, Díaz C, Quintanilla R, Cañón J, Piedrafita J (2003) Pedigree analysis of eight Spanish beef cattle breeds. Genet Sel Evol 35, 43-63

Gutiérrez JP, Goyache F (2005) A note on ENDOG: a computer program for analysing pedigree information. J Anim Breed Genet 122, 172-176

Gutiérrez JP, Marmi J, Goyache F, Jordana J (2005) Pedigree information reveals moderate to high levels of inbreeding and a weak population structure in the endangered Catalonian donkey breed. J Anim Breed Genet 122, 378-386

Gutiérrez JP, Cervantes I, Molina A, Valera M, Goyache F (2008) Individual increase in inbreeding allows estimating effective sizes from pedigrees. Genet Sel Evol 40, 359-378

Gutiérrez JP, Cervantes I, Goyache F (2009) Improving the estimation of realized effective population sizes in farm animals. J Anim Breed Genet 126, 327-332

Hussain A, Akhtar P, Ali S, Younas M, Javed K (2006a) Inbreeding effects on post-weaning growth traits of Thalli sheep in Pakistan. Pakistan J Agric Sci 43, 89-92

Hussain A, Akhtar P, Ali S, Younas M, Shafiq M (2006b) Effect of inbreeding on pre-weaning growth traits in Thalli sheep. Pakistan Vet J 26, 138-140

Kalinowski ST, Hedrick PW (2001) Inbreeding depression in captive bighorn sheep. Anim Conserv 4, 319-324

Köck A, Fürst-Waltl B, Baumung R (2009) Effects of inbreeding on number of piglets born total, born alive and weaned in Austrian Large White and Landrace pigs. Arch Tierz 52, 51-64

Lacy RC (1995) Clarification of genetic terms and their use in the management of captive populations. Zoo Biol 14, 565-577 
Lamberson WR, Thomas DL, Rowe KE (1982) The effects of inbreeding in a flock of Hampshire sheep. J Anim Sci 55, 780-786

Malécot G (1948) [The Mathematics of Heredity]. Masson et Cie press, Paris, France [in French]

Mandal A, Pant KP, Rout PK, Roy R (2004) Effects of inbreeding on lamb survival in a flock of Muzaffarnagari sheep. Asian-Aust J Anim Sci 17, 594-597

Mucha S, Wolc A, Gradowska A, Szwaczkowski T (2011) Inbreeding rate and genetic structure of cat populations in Poland. J Appl Genet 52, 101-110

Navid Ghavi HZ (2012) Inbreeding effects on body weight traits of Iranian Moghani sheep. Arch Tierz 55, 171-178

Norberg E, Sörensen AC (2007) Inbreeding trend and inbreeding depression in the Danish populations of Texel, Shropshire, and Oxford Down. J Anim Sci 85, 299-304

Oliehoek PA, Windig JJ, van Arendonk JAM, Bijma P (2006) Estimating relatedness between individuals in general populations with a focus on their use in conservation programs. Genetics 173, 483-496

Overall ADJ, Byrne KA, Pilkington JG, Pemberton JM (2005) Heterozygosity, inbreeding and neonatal traits in Soay sheep on St Kilda. Mol Ecol, 3383-3393

Pariset L, Savarese MC, Cappuccio I, Valentini A (2003) Use of microsatellites for genetic variation and inbreeding analysis in Sarda sheep flocks of central Italy. J Anim Breed Genet 120, 425-432

Pedrosa VB, Santana Jr ML, Oliveira PS, Eler JP, Ferraz JBS (2010) Population structure and inbreeding effects on growth traits of Santa Inês sheep in Brazil. Small Rumin Res 93, 135-139

Rzewuska K, Klewiec J, Martyniuk E (2005) Effect of inbred on reproduction and body weight of sheep in a closed Booroola flock. Anim Sci Pap Rep 23, 237-247

Sánchez L, Bijma P, Woolliams JA (2003) Minimizing inbreeding by managing genetic contributions across generations. Genetics 164, 1589-1595

Selvaggi M, Dario C, Peretti V, Ciotola F, Carnicella D, Dario M (2010) Inbreeding depression in Leccese sheep. Small Rumin Res 89, 42-46

Slate J, David P, Dodds KG, Veenvliet BA, Glass BC, Broad TE, McEwan JC (2004) Understanding the relationship between the inbreeding coefficient and multilocus heterozygosity: theoretical expectations and empirical data. Heredity 93, 255-265

Sörensen AC, Norberg E (2008) Inbreeding in the Danish populations of five Nordic sheep breeds. Acta Agric Scand A 58, 1-4

Swanepoel JW, van Wyk JB, Cloete SWP, Delport GJ (2007) Inbreeding in the Dohne Merino breed in South Africa. S Afr J Anim Sci 37, 176-179

Toro MA, Rodrigañez J, Silio L, Rodríguez C (2000) Genealogical analysis of a closed herd Black Hairless Iberian pigs. Conserv Biol 14, 1843-1851

VanRaden PM (1992) Accounting for inbreeding and crossbreeding in genetic evaluation for large populations. J Dairy Sci 75, 3136-3144

Van Wyk JB, Fair MD, Cloete SWP (2009) Case study: The effect of inbreeding on the production and reproduction traits in the Elsenburg Dormer sheep stud. Livest Sci 120, 218-224

Wang J, Caballero A (1999) Developments in predicting the effective size of subdivided populations. Heredity $82,212-226$

Received 3 August 2011, accepted 13 June 2012.

Corresponding author:

Abdellah Chalh

email: a.chalh@fst.rnu.tn

Unité de Génétique des Populations et Ressources Biologiques, Université Tunis El Manar, Faculté des Sciences de Tunis, Département de Biologie, Campus Universitaire, Le Belvédère, 2092, Tunis, Tunisia 